\title{
Genetic association between selected cytokine genes and glioblastoma in the Han Chinese population
}

Tianbo Jin ${ }^{1,2+}$, Xiaolan $\mathrm{Li}^{1,2+}$, Jiayi Zhang ${ }^{1,2}$, Hong Wang ${ }^{2}$, Tingting Geng ${ }^{2}$, Gang Li ${ }^{3}$, Guodong Gao ${ }^{3}$ and Chao Chen ${ }^{1,2,4^{*}}$

\begin{abstract}
Background: Glioblastoma (GBM) is the most malignant brain tumor. Many abnormal secretion and expression of cytokines have been found in GBM, initially speculated that the occurrence of GBM may be involved in these abnormal secretion of cytokines. This study aims to detect the association of cytokine genes with GBM.

Methods: We selected seven tag single nucleotide polymorphisms (tSNPs) in six cytokine genes, which previously reported to be associated with brain tumors, and analyzed their association with GBM in a Han Chinese population using $x^{2}$ test and genetic model analysis.

Results: We found two risk tSNPs and one protective tSNP. By $X^{2}$ test, the rs1801275 in IL-4R showed an increased risk of GBM. In the genetic model analysis, the genotype "TC" of rs 20541 in IL-13 gene showed an increased risk of GBM in over-dominant model $(\mathrm{OR}=2.00 ; 95 \% \mathrm{Cl}, 1.13-3.54, p=0.015)$; the genotype "CT" of rs 1800871 in the IL-10 gene showed a decrease risk in the over-dominant model $(\mathrm{OR}=0.57 ; 95 \% \mathrm{Cl}, 0.33-0.97 ; p=0.037)$. The genotype "AG" of rs 1801275 in the IL-4R gene showed an increase risk in over-dominant model $(\mathrm{OR}=2.29 ; 95 \% \mathrm{Cl}, 1.20-4.35$; $p=0.0081$ ) We further analyzed whether the six cytokine genes have a different effect on the disease in gender specific population, and found that the allele " $\mathrm{G}$ " of rs 2243248 in the IL-4 gene showed a decrease risk of GBM in female $(\mathrm{OR}=0.35,95 \% \mathrm{Cl}, 0.13-0.94, p=0.0032)$, but the allele "T" showed a decrease risk in male $(\mathrm{OR}=0.30,95 \% \mathrm{Cl}$, $0.17-0.53, p=0.0032$.
\end{abstract}

Conclusions: Our findings, combined with previously reported results, suggest that cytokine genes have potential role in GBM development, which may be useful to early prognostics for GBM in the Han Chinese population.

Keywords: Cytokine gene, Glioblastoma (GBM), Tag single nucleotide polymorphism (tSNP), Case-control study

\section{Background}

Glioblastoma (GBM) is one of the most malignant and deadly brain tumors, and occurs more commonly in adults, especially in males. According to the classification of World Health Organization, it is classified as the highest grade of IV. Although GBM has been researched for many years, the etiology of it remains unclear. It possibly arises from genetic and epigenetic alterations in

\footnotetext{
* Correspondence: cchen898@nwu.edu.cn

${ }^{\dagger}$ Equal contributors

'School of Life Sciences, Northwest University, Xi'an 710069, China

${ }^{2}$ National Engineering Research Center for Miniaturized Detection Systems,

Xi'an 710069, China

Full list of author information is available at the end of the article
}

normal astroglial cells [1], implying that the genetic factors play the mainly role in GBM genesis.

Cytokines play a significant role in cancer diagnosis, prognosis and therapy. Current studies suggest that the occurrence and development of tumors such as glioma, gastric cancer and breast cancer are associated with cytokine genes [2-5]. Many abnormal secretion and expression of cytokines have been found in GBM. To examine whether cytokine genes also contribute to risk of GBM, we selected seven tag single nucleotide polymorphisms (tSNPs) in six cytokine genes, which previously reported to be associated with glioma susceptibility $[2,4,6-10]$, to perform the study in the Han Chinese population using a case-control study.

\section{Biomed Central}

(c) 2013 Jin et al.; licensee BioMed Central Ltd. This is an Open Access article distributed under the terms of the Creative Commons Attribution License (http://creativecommons.org/licenses/by/2.0), which permits unrestricted use, distribution, and reproduction in any medium, provided the original work is properly cited. 


\section{Methods}

\section{Study population}

We recruited 72 cases newly diagnosed and histological confirmed to be GBM for the molecular epidemiology study at the department of Neurosurgery, Tangdu Hospital, affiliated with The Fourth Military Medical University in Xi'an city, China. None of them had suffered other cancer. We also selected 302 healthy unrelated individuals from the medical examination center at Tangdu Hospital. To ensure that the controls were cancer-free, we tested their presence of plasma carcinoembryonic antigen and alpha-fetoprotein. All subjects were Han Chinese, and they were selected according to detailed recruitment and exclusion criteria.

\section{Clinical data and demographic information}

A standard epidemiological questionnaire was used to collect personal data through in-person interview, including residential region, age, smoking status, gender, alcohol use, ethnicity, education status and family history of cancer. We collected the cases information through consultation with treating physicians or medical chart review. All of the participants signed informed consent. After the interview, we collected $5 \mathrm{ml}$ peripheral blood from each subject according to the study protocol approved by the Clinical Research Ethics of Northwest University.

\section{tSNP selection and genotyping}

We selected seven tSNPs from six cytokine genes, which previously published to be associated with brain tumors, with minor allele frequency (MAF) $>5 \%$ in the HapMap CHB (Chinese Han Beijing) population. DNA was extracted from whole-blood samples using GoldMag-Mini Whole Blood Genomic DNA Purification Kit according to the manufacture's protocol (GoldMag Co. Ltd. Xian, China) and concentration was measured by spectrometry (DU530UV/VIS spectrophotometer, Beckman Instruments, Fullerton, CA, USA). We used Sequenom MassARRAY Assay Design 3.0 Software to design Multiplexed SNP MassEXTENDED assay [11]. SNP genotyping was performed by Sequenom MassARRAY RS1000 using the standard protocol. Data management and analysis was performed by Sequenom Typer 4.0 Software $[11,12]$.

\section{Statistical analysis}

Genotypic frequencies in controls for each tSNP were tested for departure from Hardy-Weinberg Equilibrium (HWE) using an exact test. A $p=0.05$ was considered the threshold of statistical significance. We compared the allele frequencies of cases and controls using the $X^{2}$ test [13]. Odds Ratio (ORs) and 95\% Confidence intervals (95\% CIs) were calculated by unconditional logistic regression analysis adjusted for age and gender [14]. The most common genotype in the controls was used as reference group. The possibility of gender differences as a resource of population substructure was evaluated by a genotype test for each tSNP in males and females separately.

Statistical analyses were calculated by Microsoft Excel and SPSS 16.0 statistical package (SPSS, Chicago, IL). The associations between the cytokine genes and the risk of GBM were tested using genetic models (co-dominant, dominant, recessive, over-dominant and log-additive) analysis by SNP stats, website software from http://bioinfo. iconcologia.net/snpstats/start.htm. ORs and 95\% CIs were calculated by unconditional logistic regression analysis adjusted for age and gender [14]. Akaike's Information Criterion (AIC) and Bayesian Information Criterion (BIC) were used to determine the best-fitting model for each SNP.

\section{Results}

A multiplexed SNP MassEXTEND assay was designed with the Sequenom MassARRAY Design 3.0 Software. Seven $\mathrm{tSNPs}$ in the cytokine genes were included in GBM cases and controls. A total of 374 participants, including 72 GBM cases (44 males, 28 females; mean age at diagnosis $44 \pm 15)$ and 302 controls (119 males, 183 females; mean age $46 \pm 18$ ) were successfully genotyped for further analysis. All of the tested tSNPs are in Hardy-Weinberg equilibrium (HWE) in the controls of this study (Table 1). The average tSNPs call rate was $99.12 \%$ in both cases and controls. $X^{2}$ test revealed one tSNP was significantly

Table 1 Basic information of candidate tSNP in this study

\begin{tabular}{|c|c|c|c|c|c|c|c|c|c|c|}
\hline SNP ID & Gene name & Chromosome position & Base change & MAF - Case & MAF - Control & $p$-HWE & OR & $95 \%$ & & $P$ \\
\hline rs1800871 & IL10 & $1 \mathrm{q} 32.1$ & $\mathrm{~T} / \mathrm{C}$ & 0.340 & 0.332 & 0.095 & 1.04 & 0.71 & 1.52 & 0.854 \\
\hline rs568408 & IL12A & $3 q 25.33$ & $\mathrm{G} / \mathrm{A}$ & 0.160 & 0.159 & 0.888 & 1.00 & 0.61 & 1.64 & 0.994 \\
\hline rs20541 & IL13 & $5 q 31.1$ & $\mathrm{C} / \mathrm{T}$ & 0.285 & 0.336 & 0.970 & 0.79 & 0.53 & 1.17 & 0.237 \\
\hline rs2070874 & $\|\llcorner 4$ & $5 q 31.1$ & $\mathrm{~T} / \mathrm{C}$ & 0.201 & 0.215 & 0.851 & 1.09 & 0.69 & 1.71 & 0.715 \\
\hline rs2243248 & IL4 & $5 q 31.1$ & $\mathrm{~T} / \mathrm{G}$ & 0.056 & 0.065 & 0.520 & 0.85 & 0.39 & 1.87 & 0.689 \\
\hline rs1801275 & $\| L 4 R$ & 16p12.1 & $\mathrm{A} / \mathrm{G}$ & 0.125 & 0.196 & 0.181 & 1.71 & 1.00 & 2.92 & $0.047^{*}$ \\
\hline rs2069812 & IL5 & $5 q 31.1$ & $\mathrm{~T} / \mathrm{C}$ & 0.313 & 0.348 & 0.951 & 0.85 & 0.58 & 1.26 & 0.422 \\
\hline
\end{tabular}

MAF: minor allele frequency; OR: odds ratio; $95 \% \mathrm{Cl}$ : $95 \%$ confidence interval.

${ }^{*} p<0.05$ indicates statistical significance. 
Table 2 Single-SNP analysis

\begin{tabular}{|c|c|c|c|c|c|c|c|}
\hline Model & Genotype & $\begin{array}{c}\text { Status }=\text { Case } \\
(\mathrm{N}, \%)\end{array}$ & $\begin{array}{c}\text { Status }=\text { Control } \\
(\mathrm{N}, \%)\end{array}$ & OR $(95 \% \mathrm{CI})$ & $p$-value & AIC & $\mathrm{BIC}$ \\
\hline \multirow[t]{3}{*}{ Co-dominant } & $C / C$ & 41 (56.9\%) & $134(44.4 \%)$ & 1.00 & 0.051 & 353.0 & 372.6 \\
\hline & $\mathrm{T} / \mathrm{C}$ & $21(29.2 \%)$ & $133(44.0 \%)$ & $2.00(1.11-3.62)$ & & & \\
\hline & $\mathrm{T} / \mathrm{T}$ & 10 (13.9\%) & $35(11.6 \%)$ & $1.01(0.45-2.27)$ & & & \\
\hline \multirow[t]{2}{*}{ Dominant } & $C / C$ & 41 (56.9\%) & $134(44.4 \%)$ & 1.00 & 0.056 & 353.3 & 369.0 \\
\hline & $\mathrm{T} / \mathrm{C}-\mathrm{T} / \mathrm{T}$ & $31(43.1 \%)$ & 168 (55.6\%) & $1.68(0.99-2.86)$ & & & \\
\hline \multirow[t]{2}{*}{ Recessive } & C/C-T/C & 62 (86.1\%) & 267 (88.4\%) & 1.00 & 0.480 & 356.5 & 372.2 \\
\hline & $\mathrm{T} / \mathrm{T}$ & $10(13.9 \%)$ & $35(11.6 \%)$ & $0.75(0.35-1.64)$ & & & \\
\hline \multirow[t]{2}{*}{ Over-dominant } & $\mathrm{C} / \mathrm{C}-\mathrm{T} / \mathrm{T}$ & $51(70.8 \%)$ & 169 (56.0\%) & 1.00 & $0.015^{*}$ & 351.0 & 366.7 \\
\hline & $\mathrm{T} / \mathrm{C}$ & $21(29.2 \%)$ & $133(44.0 \%)$ & $2.00(1.13-3.54)$ & & & \\
\hline Log-additive & & & & $1.24(0.83-1.86)$ & 0.280 & 355.8 & 371.5 \\
\hline
\end{tabular}

SNP: rs20541 Percentage of typed samples: 374/374 (100\%).

rs20541 association with response status ( $n=374$, adjusted by sex + age).

${ }^{*} p<0.05$ indicates statistical significance.

associated with GBM risk at a 5\% level (rs1801275, IL4R, $\mathrm{OR}=1.71,95 \% \mathrm{CI}, 1.00-2.92, p=0.047$ ).

We assumed that the minor allele of each tSNP was a risk factor compared to the wild-type allele. MAF of cases and controls are listed in Table 1. Genetic models were applied for analyzing the association between tSNPs and GBM risk by unconditional logistic regression analysis, which adjusted for age and gender. Our results showed that the genotype "TC" of rs20541 in IL13 gene was associated with an increased risk of GBM in overdominant model $(\mathrm{OR}=2.00,95 \% \mathrm{CI}, 1.13-3.54, p=$ 0.015). The genotype "CT" of rs1800871 in IL10 gene showed a decrease risk in the over-dominant model $(\mathrm{OR}=0.57,95 \% \mathrm{CI}, 0.33-0.97, p=0.037)$. The genotype "AG" of rs1801275 in the IL4R gene showed an increase risk in the over-dominant model $(\mathrm{OR}=2.29,95 \% \mathrm{CI}, 1.20$ $4.35, p=0.0081$ ), (Tables 2, 3 and 4).
We further analyzed whether the seven tSNPs have a different effect on GBM risk in gender specific population, and found that the allele "G" of rs2243248 in the $I L-4$ gene showed a decrease risk in female $(\mathrm{OR}=0.35$, 95\% CI,0.13 - 0.94, $p=0.0032$ ), but the allele "T" showed a decrease risk in male $(\mathrm{OR}=0.30,95 \% \mathrm{CI}, 0.17-0.53$, $p=0.0032)$ (Table 5).

\section{Discussion}

We genotyped seven tSNPs in this case-control study in the Han Chinese population, and found two risk tSNPs and one protective tSNP using genetic model analysis. In addition, we also found one tSNP have different risk effect on GBM in gender specific population. All the results suggested that the polymorphisms of these cytokine genes may play an important role in the risk of GBM in the Han Chinese population.

Table 3 Single-SNP analysis

\begin{tabular}{|c|c|c|c|c|c|c|c|}
\hline Model & Genotype & $\begin{array}{c}\text { Status }=\text { Case } \\
(\mathrm{N}, \%)\end{array}$ & $\begin{array}{c}\text { Status }=\text { Control } \\
(\mathrm{N}, \%)\end{array}$ & OR (95\% Cl) & $p$-value & AIC & $\mathrm{BIC}$ \\
\hline \multirow[t]{3}{*}{ Co-dominant } & $\mathrm{T} / \mathrm{T}$ & $29(40.3 \%)$ & $141(47.3 \%)$ & 1.00 & 0.10 & 353.1 & 372.7 \\
\hline & $\mathrm{C} / \mathrm{T}$ & 37 (51.4\%) & 116 (38.9\%) & $0.59(0.34-1.03)$ & & & \\
\hline & $\mathrm{C} / \mathrm{C}$ & $6(8.3 \%)$ & 41 (13.8\%) & $1.23(0.47-3.23)$ & & & \\
\hline \multirow[t]{2}{*}{ Dominant } & $\mathrm{T} / \mathrm{T}$ & $29(40.3 \%)$ & $141(47.3 \%)$ & 1.00 & 0.16 & 353.7 & 369.3 \\
\hline & $\mathrm{C} / \mathrm{T}-\mathrm{C} / \mathrm{C}$ & $43(59.7 \%)$ & 157 (52.7\%) & $0.68(0.40-1.17)$ & & & \\
\hline \multirow[t]{2}{*}{ Recessive } & $\mathrm{T} / \mathrm{T}-\mathrm{C} / \mathrm{T}$ & $66(91.7 \%)$ & 257 (86.2\%) & 1.00 & 0.29 & 354.5 & 370.2 \\
\hline & $\mathrm{C} / \mathrm{C}$ & $6(8.3 \%)$ & $41(13.8 \%)$ & $1.61(0.64-4.01)$ & & & \\
\hline \multirow[t]{2}{*}{ Over-dominant } & $\mathrm{T} / \mathrm{T}-\mathrm{C} / \mathrm{C}$ & $35(48.6 \%)$ & $182(61.1 \%)$ & 1.00 & $0.037^{*}$ & 351.3 & 366.9 \\
\hline & $\mathrm{C} / \mathrm{T}$ & 37 (51.4\%) & 116 (38.9\%) & $0.57(0.33-0.97)$ & & & \\
\hline Log-additive & & & & $0.90(0.61-1.32)$ & 0.59 & 355.4 & 371.0 \\
\hline
\end{tabular}

SNP: rs1800871 Percentage of typed sample: $370 / 374$ (98.93\%).

rs 1800871 association with response status ( $n=370$, adjusted by sex + age).

${ }^{*} p<0.05$ indicates statistical significance. 
Table 4 Single-SNP analysis

\begin{tabular}{|c|c|c|c|c|c|c|c|}
\hline Model & Genotype & $\begin{array}{c}\text { Status = Case } \\
(\mathrm{N}, \%)\end{array}$ & $\begin{array}{c}\text { Status }=\text { Control } \\
(\mathrm{N}, \%)\end{array}$ & OR $(95 \% \mathrm{Cl})$ & $p$-value & AIC & BIC \\
\hline \multirow[t]{3}{*}{ Co-dominant } & $\mathrm{A} / \mathrm{A}$ & $56(77.8 \%)$ & $187(62.8 \%)$ & 1.00 & 0.028 & 350.1 & 369.6 \\
\hline & $\mathrm{A} / \mathrm{G}$ & $14(19.4 \%)$ & 105 (35.2\%) & $2.26(1.19-4.32)$ & & & \\
\hline & $\mathrm{G} / \mathrm{G}$ & $2(2.8 \%)$ & $6(2.0 \%)$ & $0.72(0.13-4.02)$ & & & \\
\hline \multirow[t]{2}{*}{ Dominant } & A/A & $56(77.8 \%)$ & $187(62.8 \%)$ & 1.00 & 0.016 & 349.4 & 365.1 \\
\hline & $\mathrm{A} / \mathrm{G}-\mathrm{G} / \mathrm{G}$ & $16(22.2 \%)$ & 111 (37.2\%) & $2.07(1.12-3.83)$ & & & \\
\hline \multirow[t]{2}{*}{ Recessive } & $\mathrm{A} / \mathrm{A}-\mathrm{A} / \mathrm{G}$ & 70 (97.2\%) & $292(98.0 \%)$ & 1.00 & 0.550 & 354.9 & 370.5 \\
\hline & $\mathrm{G} / \mathrm{G}$ & $2(2.8 \%)$ & $6(2.0 \%)$ & $0.58(0.10-3.23)$ & & & \\
\hline \multirow[t]{2}{*}{ Over-dominant } & $\mathrm{A} / \mathrm{A}-\mathrm{G} / \mathrm{G}$ & $58(80.6 \%)$ & $193(64.8 \%)$ & 1.00 & $0.0081^{*}$ & 348.2 & 363.9 \\
\hline & $\mathrm{A} / \mathrm{G}$ & $14(19.4 \%)$ & 105 (35.2\%) & $2.29(1.20-4.35)$ & & & \\
\hline Log-additive & & & & $1.76(1.00-3.10)$ & 0.042 & 351.1 & 366.7 \\
\hline
\end{tabular}

SNP: rs1801275 Percentage of typed samples: $370 / 374$ (98.93\%).

rs 1801275 association with response status ( $n=370$, adjusted by sex + age).

Note: AIC: Akaike Information Criterion; BIC: Bayesian Information Criterion.

${ }^{*} p<0.05$ indicates statistical significance.

Interleukins are a part of cytokine, encoded by interleukin genes and produced by a variety of cells. They can deliver information, activate and regulate immune cells, mediate $\mathrm{T}$ and $\mathrm{B}$ cells activation, proliferation and differentiation. Cytokines play a significant role in cancer diagnosis, prognosis and therapy. The immune system's failure to recognize the malignant tumor cells and perform an effective response may be the result of tumorassociated cytokine deregulation [15].

IL10 (interleukin-10) has pleiotropic effect in immunoregulation and inflammation, which plays a key role in immunosuppressive and antiangiogenic process, suggesting its possible involvement in carcinogenesis [16]. It has been demonstrated that polymorphisms of the $I L-10$ gene are associated with multiple cancer, such as gastric cancer, non-small cell lung cancer and breast cancer $[3,17-20]$, and our results indicating that the polymorphisms of $I L-10$ are associated with GBM.

IL13 encodes IL-13, an immunoregulatory cytokine produced primarily by activated Th2 cells. IL-13 is thought to the pathogenesis of allergen-induced asthma [21]. Besides, the polymorphisms of $I L-13$ involved in some other diseases, such as eczema, allergic rhinitis [22,23]. GBM etiology remains unclear, but IL-13 has been shown to be over expressed in a majority of glioma cell lines and GBM tumor tissues [15]. There are consistent reports of inverse association between risk of adult glioma and personal history of allergy and autoimmune disease, but the molecular mechanism still unclear, there still need further investigate.

IL-4 is a ligand for interleukin-4 receptor, inducing macrophage activation and synergizing with colonystimulating factors in promoting the growth of hematopoietic cells. Previously researches have suggested the IL-4 polymorphisms were significantly associated with the risk of adult glioma [4]. Another report showed that IL-4 induced an aberrant activation of Stat3 in GBM cells but not in normal human astrocytes, and speculated that IL-4 induce aberrant activation of Stat3 may contribute to the pathogenesis of GBM cells [8].

$I L 4 R$ encodes the alpha chain of the interleukin- 4 receptor that can bind interleukin 4 and interleukin 13 to regulate IgE production [24]. A soluble form of the encoded protein can inhibit IL-4 mediated cell proliferation. In our study rs1801275 in the IL4R gene can predict 2.29-fold GBM susceptibility by the over-dominant model. In addition, another article also reported rs1801275 could increase the risk of GBM $(\mathrm{OR}=1.61,95 \% \mathrm{CI}, 1.05$ 2.47) in a population-based case-control study [25], it is consistent with our results that $I L-4$ gene are associated with GBM.

Helper T (Th) cell can secret multiple cytokines. Th1 cell mainly produced IL-2, IFN- $\gamma$ and TNF, mediating cellular immune response and involving in delayed type

Table 5 Association between sex and the risk of GBM in the rs2243248

\begin{tabular}{|c|c|c|c|c|c|c|}
\hline & \multicolumn{3}{|c|}{ Female } & \multicolumn{3}{|c|}{ Male } \\
\hline & Status $=$ Case & Status $=$ Control & OR $(95 \% \mathrm{Cl})$ & Status $=$ Case & Status $=$ Control & OR $(95 \% \mathrm{Cl})$ \\
\hline $\mathrm{T} / \mathrm{T}$ & 21 & 160 & 1.00 & 43 & 103 & $0.30(0.17-0.53)$ \\
\hline $\mathrm{G} / \mathrm{T}$ & 7 & 23 & $0.35(0.13-0.94)$ & 1 & 16 & $1.78(0.22-14.26$ \\
\hline
\end{tabular}

rs2243248 and sex cross-classification interaction table $(n=374$, adjusted by age). Interaction p-value: 0.0032 . 
hypersensitivity [26]. Th2 cell secreted $I L-4, I L-6, I L-10$ and $I L-13$, mainly mediating humoral immune response [26]. Under normal circumstance, Th1 and Th2 cytokines are in dynamic equilibrium. In the anti-tumor immunity Th1 cytokines should have a more important role. But in glioma tissues, there is obviously predominant expression of Th2 type cytokines, it may result tumor cells escape from immune response, so the abnormal secretion of $I L-4, I L-10$ and $I L-13$ may play an important role in the occurring and developing of human glioma $[27,28]$. Besides, previously results showed that IL4, IL4R and IL13 genes may play an important role in glioma survival [29]. All of these suggest multiple cytokines are associated with tumor development and progression survival.

In addition, gender difference should be considered in the association analysis, because many genes have been demonstrated function differently in male and female. Such as 5-HTTLPR gene, females with the 1/s genotype showed higher anxiety than those with the s/s genotype in both state and trait anxiety. Oppositely, males with the $\mathrm{s} / \mathrm{s}$ genotype showed high anxiety than those with the $1 / \mathrm{s}$ genotype [30]. The human gene $B D N F$ genotyping 196G/G carriers can increase the risk of multiple sclerosis only in females, but not in males [31]. However, few researches take gender difference into consideration in association analysis of susceptibility gene. We analyzed whether cytokine genes have different effect on GBM in gender specific population, and found that the allele "G" of rs2243248 in the $I L-4$ gene showed a decrease risk of GBM in female $(\mathrm{OR}=0.35,95 \% \mathrm{CI}, 0.13$ $0.94, p=0.0032)$, but the allele " $\mathrm{T}$ " showed a decrease risk in male $(\mathrm{OR}=0.30,95 \% \mathrm{CI}, 0.17-0.53, p=0.0032)$. We speculated that the expression of $I L-4$ polymorphisms maybe regulated by sex hormone.

\section{Conclusions}

In conclusion, our findings combined with previously results, suggest that the polymorphisms of cytokine genes have potential role in GBM development, and we advocate that gender difference should be taken into consideration in research of susceptible gene. However, the exact function of the polymorphisms of the genes and the regulatory mechanism for gene expression have not been researched clearly, the molecular mechanisms still need to be further investigated.

\section{Abbreviations}

GBM: Glioblastoma; tSNP: Tag single nucleotide polymorphism; OR: Odd ratio; 95\% Cl: 95\% confidence interval.

\section{Competing interests}

The authors declare that they have no competing interests.

\section{Authors' contributions}

TBJ: conceived in the design of study, and performed the data management. $\mathrm{XLL}$ : participated in the design of study, and draft the manuscript. JYZ: participated in the design of study and helped to draft the manuscript. HW: designed the primers and carried out the genetic study. TTG: carried out the genetic study. GL: collected the blood samples and participated in the design of study. GDG: collected the blood samples, and participated in the design of study. CC: conceived in the design of the study. All authors read and approved the final manuscript.

\section{Acknowledgements}

This work is supported by the National 863 High-Technology Research and Development Program (No. 2012AA02A519). We are grateful to all the patients and individuals for their participation. We would also like to thank the clinicians and other hospital staff who contributed to the blood sample and data collection for this study.

\section{Author details}

${ }^{1}$ School of Life Sciences, Northwest University, Xi'an 710069, China. ${ }^{2}$ National Engineering Research Center for Miniaturized Detection Systems, Xi'an 710069, China. ${ }^{3}$ Department of Neurosurgery, Tangdu hospital, the Fourth Military Medical University, Xi'an 710038, China. ${ }^{4}$ Mailbox 386, \#229 North Taibai Road, Xi'an 710069, Shaanxi, China.

Received: 1 December 2012 Accepted: 8 May 2013 Published: 12 May 2013

\section{References}

1. Haque A, Banik NL, Ray SK: Chapter 5- Molecular Alterations in Glioblastoma: Potential Targets for Immunotherapy. Prog Mol Biol Trans/ Sci 2011, 98:187-234

2. Li SQ, Jin TB, Zhang JY, Lou HL, Yang B, Li Y, Chen C, Zhang YS: Polymorphisms of TREH, IL4R and CCDC26 genes associated with risk of glioma. Cancer Epidemiol 2012, 36(3):283-287.

3. Yuan LJ, Jin TB, Yin JK, Du XL, Wang Q, Dong R, Wang SZ, Cui Y, Chen C, Lu JG: Polymorphisms of tumor-related genes IL-10, PSCA, MTRR and NOC $3 \mathrm{~L}$ are associated with the risk of gastric cancer in the Chinese Han population. Cancer Epidemiol 2012, 36(6):366-372.

4. Brenner AV, Butler MA, Wang SS, Ruder AM, Rothman N, Schulte PA, Chanock SJ, Fine HA, Linet MS, Inskip PD: Single-nucleotide polymorphisms in selected cytokine genes and risk of adult glioma. Carcinogenesis 2007, 28(12):2543-2547.

5. Al-Rawi MAA, Rmali K, Watkins G, Mansel RE, Jiang WG: Aberrant expression of interleukin-7 (IL-7) and its signalling complex in human breast cancer. Eur J Cancer 2004, 40(4):494-502.

6. Vleeschouwer SD, Lopes LS, Ceuppens JL, Gool SW: Persistent IL-10 production is required for glioma growth suppressive activity by Th1-directed effector cells after stimulation with tumor lysate-loaded dendritic cells. J Neurooncol 2007, 84(2):131-140.

7. Amirian E, Liu YH, Scheurer ME, El-Zin R, Gilbert MR, Bondy ML: Genetic variants in inflammation pathway genes and asthma in glioma susceptibility. Neuro Oncol 2009, 12(5):444-452.

8. Rahaman SO, Vogelbaum MA, Haque SJ: Aberrant Stat3 Signaling by interleukin-4 in Malignant Glioma Cells: Involvement of IL-13Ra2. Cancer Res 2005, 65:2956.

9. Sima XT, Xu JG, Li Q, Luo L, Liu JG, You C: Gene-gene interactions between interleukin-12A and interleukin-12 $B$ with the risk of brain tumor. DNA Cell Biol 2012, 31(2):219-223.

10. Sun G, Wang XF, Shi L, Yue X, Fu LS, Chen C, Li ZY, Pan TH, Wan ZQ: Association between polymorphisms in interleukin-4Ra and interleukine13 and glioma risk: A meta-analysis. Cancer Epidemio/ 2013, 37(3):306-310.

11. Gabriel S, Ziaugra L, Tabbaa D: UNIT 2.12 SNP Genotyping Using the Sequenom MassARRAY iPLEX Platform. Curr Protoc Hum Genet 2009. doi:10.1002/0471142905.hg0212s60.

12. Thomas RK, Baker AC, DeBiasi RM, Winckler W, LaFramboise T, Lin WM: High-throughput oncogene mutation profiling in human cancer. Nat Genet 2007, 39:347-351.

13. Adamec C: Example of the use of the nonparametric test: Test $x 2$ for comparison of 2 independent examples. Cesk Zdrav 1964, 12:9-613.

14. Bland JM, Altman DG: Statistics notes. The odds ratio. Br Med J 2000, 320:1468. 
15. Zhu VF, Yang JX, LeBrun DG, Li M: Understanding the role of cytokines in Glioblastoma Multiforme pathogenesis. Cancer Lett 2012, 316(2):139-150.

16. Xue HP, Lin B, An JF, Zhu YY, Huang G: Interleukin-10-819 promoter polymorphisms in association with gastric cancer risk. BMC Cancer 2012, 12:102.

17. Zeng XT, Li YM, LiU T, Zhang JQ: Diverse H. pylori strains, IL-10 promoter polymorphisms with high morbidity of gastric cancer in Hexi area of Gansu Province, China. Mol Cell Biochem 2012, 362:241-248.

18. Zhou Y, Hu W, Zhuang W, Wu XT: Interleukin-10-1082 promoter polymorphisms and gastric cancer risk in a Chinese Han population. Mol Cell Biochem 2011, 347:89-93.

19. Shih CM, Lee YL, Chiou HL, Hsu WF, Chen WE, Chou MC, Lin LY: The involvement of genetic polymorphism of IL-10 promoter in non-small cell lung cancer. Lung Cancer 2005, 50(3):291-297.

20. Pooja S, Chaudhary P, Navak LV, Rajender S, Saini KS, Deol D: Polymorphic variations in IL-1 $\beta, \mathrm{IL}-6$ and IL-10 genes, their circulating serum levels and breast cancer risk in Indian women. Cytokine 2012, 60(1):122-128.

21. Cui L, Jia J, Ma CF, Li SY, Wang YP, Guo XM, Li Q, Yu HB, Liu WH, Gao LB: IL-13 polymorphisms contribute to the risk of asthma: a meta-analysis. Clin Biochem 2012, 45(4-5):285-288.

22. Miyakea Y, Kiyohara C, Koyanagib M, Fujimotob T, Shirasawab S, Tanakaa K Sasaki S, Hirota Y: Case-control Study of Eczema Associated with IL-13 Genetic Polymorphisms in Japanese Children. Allergy Immunol 2011, 154:328-335.

23. Kim WK, Kwon JW, Seo JH, Kim HY, Yu J, Kim BJ, Kim HB, Lee SY, Kim KW, Kang MJ: Interaction between IL-13 genotype and environmental factors in the risk for allergic rhinitis in Korean children. J Allergy Clin Immunol 2012, 130(2):421-426.

24. Choi WA, Kang MJ, Kim YJ, Seo JH, Kim HY, Kwon JW, Yu J, Park SJ, Lee YC, Hong SJ: Gene-gene interactions between candidate gene polymorphisms are associated with total lgE levels in Korean children with asthma. J Asthma 2012, 49(3):243-252.

25. Schwartzbaum J, Ahlbom A, Malmer B, Lonn S, Brookes AJ, Doss H: Polymorphisms Associated with Asthma Are Inversely Related to Glioblastoma Multiforme. Cancer Res 2005, 65:6459.

26. Wilczynski JR: Th1/Th2 cytokine balance-yin and yang of reproductive immunology. Eur J Obstet Gyn R B 2005, 122(2):136-143.

27. Li G, Hu YS, Li XG, Zhang QL, Wang DH, Gong SF: Expression and switching of TH1/TH2 type cytokines gene in human glioma. Chin Acad Med Sci 2005, 20(4):268-272.

28. Li G, Hu YS, Li XG, Zhang QL, Jia DZ, Gong SF: The role of predominant expression of Th2 type cytokines gene in the genesis and development of human gliomas. Chin-Ger J Clin Oncol 2003, 2(4):227-236.

29. Scheurer ME, Amirian E, Cao YM, Gilbert MR, Aldape KD, Kornguth DG, El-Zein R, Bondy ML: Polymorphisms in the Interleukin-4 Receptor Gene are Associated with Better Survival in Patients with Glioblastoma. Clin Cancer Res 2008, 14:6640.

30. Mizuno T, Aoki M, Shimada Y, Inoue M, Nakaya K, Takahashi T, Itoyama Y, Kanazawa M, Utsumi A, Endo Y, et al: Gender difference in association between polymorphism of serotonin transporter gene regulatory region and anxiety. J Psychosom Res 2006, 60(1):91-97.

31. Mirowska-Guzel D, Mach A, Gromadzka G, Czlonkowski A, Czlonkowska A: BDNF A196G and C270 T gene polymorphisms and susceptibility to multiple sclerosis in the polish population. Gender difference. J Neuroimmunol 2008, 193(1-2):170-172.

doi:10.1186/1471-2407-13-236

Cite this article as: Jin et al:: Genetic association between selected cytokine genes and glioblastoma in the Han Chinese population. BMC Cancer 2013 13:236.

\section{Submit your next manuscript to BioMed Central and take full advantage of:}

- Convenient online submission

- Thorough peer review

- No space constraints or color figure charges

- Immediate publication on acceptance

- Inclusion in PubMed, CAS, Scopus and Google Scholar

- Research which is freely available for redistribution

Submit your manuscript at www.biomedcentral.com/submit
Biomed Central 